\title{
ANALISIS KELAYAKAN USAHA AGROINDUSTRI TAHU DI DESA KUANTAN SAKO KECAMATAN LOGAS TANAH DARAT KABUPATEN KUANTAN SINGINGI (Studi Kasus Pada Usaha Agroindustri Tahu Mbak Rubingah)
}

\author{
ANALYSIS OF KNOWLEDGE FEASIBILITY OF AGROINDUSTRY BUSINESSIN \\ THE VILLAGE OF KUANTAN SAKO, LOGAS TANAH DARAT DISTRICT, \\ KUANTAN SINGINGI DISTRICT \\ (Case Study on Tofu Agroindustry Business Mbak Rubingah)
}

\author{
Fajar Pebriansyah, Elfi Indrawanis, Mahrani \\ Agriculture Faculty Agribusiness Study Program \\ Kuantan Singingi Islamic University \\ fajarpbr@gmail.com
}

\begin{abstract}
ABSTRAK
Penelitian ini dilaksanakan di Desa Kuantan Sako Kecamatan Logas Tanah Darat Kabupaten Kuantan Singingi, yang dilaksanakan pada bulan Februari sampai dengan April 2019. Tujuan penelitian ini adalah untuk mengetahui analisis kelayakan secara finansial (NPV, Net B/C, PR, PBP dan BEP) usaha agroindustri tahu di Desa Kuantan Sako Kecamatan Logas Tanah Darat Kabupaten Kuantan Singingi. Hasil Penelitian Analisis kelayakan Agroindustri Tahu Mbak Rubingah di Desa Kuantan Sako Kecamatan Logas Tanah Darat berdasarkan Net Present Value (NPV), Net B/C Ratio dan Profitability Ratio memiliki nilai positif dimana Agroindustri Tahu Mbak Rubingah sangat layak untuk dijalankan, hal ini dapat diihat pada nilai Net Present Value (NPV) adalah Rp 2.303.553.375.31, nilai Net B/C Ratio sebesar 1.85, nillai Profitability Ratio sebesar 28.96 yang bergerak positif. Untuk Pay Back Period (PBP) Agroindustri Tahu Mbak Rubingah pada 2 bulan 28 hari. Sedangkan Break Event Point (BEP) Agroindustri Tahu Mbak Rubingah pada 2 tahun 6 bulan.
\end{abstract}

Kata Kunci : Agroindustri Tahu; Kuantan Sako; Studi Kelayakan Usaha

\begin{abstract}
This research was conducted in Kuantan Sako Village, Logas Tanah Darat District, Kuantan Singingi Regency, which was held from February to April 2019. The purpose of this study was to determine the financial feasibility analysis (NPV, Net B / C, PR, PBP and BEP) tofu agroindustry in Kuantan Sako Village, Logas Tanah Darat District, Kuantan Singingi Regency. The research results of the feasibility analysis of Tahu Agroindustri Mbak Rubingah in Kuantan Sako Village, Logas Tanah Darat District based on the Net Present Value (NPV), Net B I C Ratio and Profitability Ratio have positive values where Tahu Agroindustri Mbak Rubingah is very feasible to run, this can be seen in The Net Present Value (NPV) value is Rp 2.303.553.375.31, the Net B / C Ratio value is 1.85, and the Profitability Ratio is 28.96 which is positive. Tofu Agroindustry Pay Back Period
\end{abstract}


(PBP) Mbak Rubingah at 2 months 28 days. While the Break Event Point (BEP) of Tofu Agroindustry Mbak Rubingah at 2 years 6 months.

Keywords: Tofu Agroindustry; Kuantan Sako; Business Feasibility Study

\section{PENDAHULUAN}

Agroindustri merupakan suatu bentuk kegiatan atau aktifitas pengolahan bahan baku yang berasal dari tanaman maupun hewan. Definisi agroindustri terbagi dalam dua hal, yaitu pertama agroindustri sebagai industri yang berbahan baku utama dari produk pertanian dan kedua agroindustri sebagai suatu tahapan pembangunan sebagai kelanjutan dari pembangunan pertanian tetapi belum mencapai tahapan pembangunan industri (Soekartawi, 2000).

Kedelai merupakan bahan pangan yang banyak dikonsumsi seperti makanan olahan dari kedelai salah satunya tahu.Usaha pembuatan tahu dirasa memberikan kontribusi pendapatan yang baik bagi produsen karena permintaan tahu tidak pernah turun, sehingga meningkatkan taraf hidup pengusaha serta banyak dari produsen ingin mengembangkan usaha untuk kedepannya melalui pemasaran yang optimal (Cahyadi, 2007).

Kabupaten Kuantan Singingi merupakan salah satu Kabupaten yang terletak di Selatan Provinsi Riau yang memiliki perkembangan agroindustri yang cukup tinggi dengan memanfaatkan bahan baku pertanian dalam kegiatan pengolahan. Salah satu kegiatan agroindustri di Kabupaten Kuantan Singingi adalah industri pengolahan kacang kedelai menjadi tahu.Agroindustri tahu yang berkembang di Kabupaten Kuantan
Singingi saat ini memiliki prospek yang menjanjikan.

Desa Kuantan Sako Kecamatan Logas Tanah Darat Kabupaten Kuantan Singingi merupakan lokasi pengembangan agroindustri tahu, dimana Desa Kuantan Sako pada saat ini memiliki 5 unit agroindustri tahu. Dari 5 agroindustri tahu hanya satu tempat yang akan dijadikan tempat penelitian ini yaitu agroindustri tahu Mbak Rubingah dengan jumlah produksi rata rata $50 \mathrm{~kg} / \mathrm{hari}$.

Permasalahan pokok yang menghambat perkembangan agroindustri tahu Mbak Rubingah saat ini adalah pengaruh modal kerja yang sangat minim.

Agroindustri tahu Mbak Rubingah dalam memproduksi tahu juga memiliki permasalahan terhadap rendahnya modal sehingga agroindustri tahu Mbak Rubingah tidak mampu memproduksi dengan lancar, hal ini dalam memproduksi tahu menunggu adanya permintaan pasar.

Kenaikan harga bahan baku agroindustri tahu Mbak Rubingah yaitu kacang kedelai yang selalu meningkat dapat menghambat berjalannya usaha agroindustri tahu. peningkatan bahan baku tambahan yang dibutuhkan dalam menunjang pengolahan agroindustri tahu seperti bahan bakar, cuka dan lainnya yang seringkali langka dan meningkatnya harga bahan baku yang membuat pelaku usaha menghentikan sementara proses pengolahan agroindustri tahu hingga keadaan normal. 
Permasalahan agroindustri tahu Mbak Rubingah saat ini belum memiliki izin DinKes sehingga hasil produksi belum memiliki hasil uji kesehatan kehigenisan standar gizi untuk memperoleh izin.Hal ini sulitnya memperoleh izin DinKes mempengaruhi terhadap kwalitas tahu yang diproduksi oleh agroindustri tahu Mbak Rubingah.

Melihat permasalahan tersebut dipandang perlu dilakukan suatu kajian dari kegiatan usaha agroindustri tahu yang dihasilkan oleh agroindustri tahu Mbak Rubingah dalam menganalisis keuntungan dan kelayakan usaha yang didapat dari pengolahan agroindustri tahu. Dengan demikian maka penulis tertarik melakukan penelitian tentang " Analisis Kelayakan Usaha Agroindustri Tahu Di Desa Kuantan Sako Kecamatan Logas Tanah Darat Kabupaten Kuantan Singingi”.

\section{Rumusan Masalah}

Dari uraian pada latar belakang maka dapat dirumuskan beberapa masalah yang dapat di teliti, yaitu seberapa besar analisis kelayakan secara finansial (NPV, Net $\mathrm{B} / \mathrm{C}$, PR, PBP dan BEP) usaha agroindustri tahu di Desa Kuantan Sako Kecamatan Logas Tanah Darat Kabupaten Kuantan Singingi?

\section{Tujuan Penelitian}

Tujuan penelitian adalah untuk menganalisis kelayakan secara finansial (NPV, Net B/C, PR, PBP dan BEP) usaha agroindustri tahu di Desa Kuantan Sako Kecamatan Logas Tanah Darat Kabupaten Kuantan Singingi.

\section{Ruang Lingkup Penelitian}

Fokus penelitian adalah pada usaha agroindustri tahu yang dimiliki oleh Mbak Rubingah di Desa Kuantan Sako Kecamatan Logas Tanah Darat Kabupaten Kuantan Singingi.Data biaya produksi dan harga dianalisis berdasarkan pada tahun produksi. Analisis finansial usaha agroindustri tahu Mbak Rubingah yang digunakan adalah NPV, Net B/C, PR, PBP dan BEP pada tahun 2011 sampai dengan 2018 dengan suku bunga BI 6,75\% pada tahun mulai berinvestasi.

\section{METODE PENELITIAN Tempat Dan Waktu Penelitian}

Penelitian dilakukan di Desa Kuantan Sako Kecamatan Logas Tanah Darat Kabupaten Kuantan Singingi, Penelitian ini dilaksanakan selama 5 bulan terhitung pada bulan Februari 2019 sampai bulan Juni 2019.

\section{Metode Penentuan Sampel}

Metode pengambilan sampel dilakukan secara proposive, dimana usaha agroindustri tahu yang berada Di Desa Kuantan Sako Kecamatan Logas Tanah Darat terdapat 5 usaha agroindustri tahu dengan sampel penelitian hanya 1 agroindustri tahu Mbak Rubingah dikarenakan aktif, produksi tahu terbesar dan usia pemilik agroindustri tahu Mbak Rubingah produktif. Penelitian ini merupakan penelitian studi kasus dimana peneliti terfokus pada 1 usaha agroindustri tahu.

\section{Jenis Dan Sumber Data}

Data yang dikumpul berupa data primer dan data sekunder.Data primer merupakan data yang diambil langsung dari pelaku usaha agroindustri tahu meliputi identitas responden (umur, jenis kelamin, 
pendidikan dan tanggungan keluarga), jenis dan biaya produksi, tenaga kerja, harga produksi dan lainnya yang berkaitan dengan penelitian ini. Sedangkan data sekunder adalah data yang diperoleh data instansi terkait meliputi keadaan penduduk, tingkat pendidikan, keadaan perekonomian, dan kelembagaan daerah penelitian yang dianggap perlu dalam mendukung proses perlengkapan penelitian.

\section{Analisis Data}

Analisis data yang digunakan dalam penelitian adalah analisis data kwantitatif dianalisis secara matematik. Adapun analisis yang digunakan dalam menganalisis data adalaha kelayakan usaha agroindustri tahu secara finansial yaitu :

\section{Discount Faktor (DF)}

Discount factor (Df) adalah suatu faktor bilangan lebih kecil dari suatu yang dapat digunakan untuk menghitung sutau nilai masa datang, berapa nilainya saat ini, dengan memperhitungkan tingkat bunga yang tetap pada akhir tahun. Formulasi aljabar dari discounting factor adalah sebagai berikut :

$\mathrm{DF}=1 /(1+\mathrm{i})^{\wedge \mathrm{n}}$

Dimana :

DF $=$ Diskount Faktor

i = Nilai Suku Bunga Investasi

$\mathrm{n}=$ Tahun investasi

\section{Net Present Value (NPV)}

Net Present Value (NPV) suatu proyek atau usaha adalah selisih antara nilai sekarang (present value) manfaat dengan arus biaya.NPV juga dapat diartikan sebagai nilai sekarang dari arus kas yang ditimbulkan oleh investasi.Perhitungan NPV perlu ditentukan tingkat bunga yang relevan.

Bimlana: $: \sum_{i=1}^{n} N B_{i}(1+i)^{-n}$

atay $\mathrm{NB}=$ Net benefit =

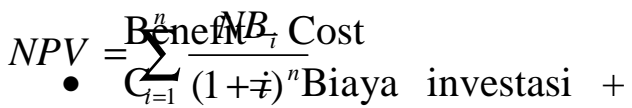
atau Biaya operasi

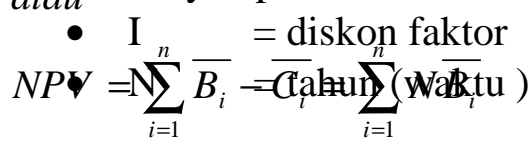

Kriteria kelayakan berdasarkan NPV yaitu:

a. NPV > 0, artinya suatu proyek sudah dinyatakan menguntungkan dan layak untuk dijalankan.

b. NPV < 0, artinya proyek tersebut tidak menghasilkan nilai biaya yang dipergunakan. Dengan kata lain, proyek tersebut merugikan dan tidak layak untuk dijalankan.

c. $\mathrm{NPV}=0$, artinya proyek tersebut mampu mengembalikan persis sebesar modal sosial opportunity cost faktor produksi normal. Dengan kata lain, proyek tersebut tidak untung dan tidak rugi.

\section{Net Benefit/Cost Ratio (Net B/C)}

Net B/C yaitu membagi jumlah nilai sekarang aliran kas manfaat bersih positif dengan jumlah nilai sekarang aliran kas manfaat bersih negatif pada tahun- tahun awal proyek. Rumus yang digunakan adalah: 


$$
\begin{aligned}
& \operatorname{Net} \frac{\mathrm{B}}{\mathrm{C}}=\frac{\sum=0 \frac{-}{(1+)}}{\sum=0 \frac{-}{(1+)}} \\
&=\frac{\sum=1 \quad}{\sum_{=1} \longrightarrow(+)} \\
&=
\end{aligned}
$$

Dimana:

Net $\mathrm{B} / \mathrm{C}=$ Net Benefit Cost Ratio

$\mathrm{Bt}=$ Benefit atau penerimaan tahun $\mathrm{t}$

$\mathrm{Ct}=$ Cost atau biaya pada tahun $\mathrm{t}$

$\mathrm{i}=$ Tingkat suku bunga

$\mathrm{t}=$ Tahun (waktu ekonomis)

Kriteria penilaian dalam analisis ini adalah:

1) Jika Net B/C lebih besar dari satu maka usaha dinyatakan layak

2) Jika Net B/C lebih kecil dari satu maka usaha dinyatakan tidak layak

3) Jika Net B/C sama dengan satu maka usaha dinyatakan dalam posisi impas.(Gittingar:1986)

\section{Profitability Ratio (PR)}

Profitability Ratio adalah rasio perbandingan antara selisih benefit dengan biaya operasi dan pemeliharaan dengan jumlah investasi. Nilai dari masng-masing variabel dalam bentuk present value (telah didiskon dengan DF dari SOCC).

Rumus:

$$
=\frac{\sum_{=1} \overrightarrow{-}-\sum_{=1} \overrightarrow{-}}{\sum_{=1}}
$$

Jika:

PR > 1 (satu) berarti proyek (usaha) layak dikerjakan

PR < 1 (satu) berarti proyek tidak layak dikerjakan
$\mathrm{PR}=1$ (satu) berarti proyek dalam keadaan BEP.

\section{Pay Back Period (PBP)}

Pay Back Period adalah pengembangan jangka waktu tertentu yang menunjukkan terjadinya arus penerimaan (cash in flows) yang secara kumulatif sama dengan jumlah investasi dalam bentuk present value.

Rumus:

$$
+\underbrace{\sum_{=1}^{-1}-\sum_{=1} \rightarrow-1}_{=1}
$$

Dimana:

PBP = Pay Back Period

$\mathrm{T}_{\mathrm{p}-1} \quad=$ Tahun sebelum terdapat PBP

$\mathrm{I}_{\mathrm{i}} \quad=$ Jumlah investasi telah didiskon

$\mathrm{B}_{\text {icp-1 }}=$ Jumlah benefit yang telah didiskon sebelum PBP

$\mathrm{B}_{\mathrm{p}}=$ Jumlah benefit pada PBP

\section{Break Even Point (BEP)}

Titik pulang pokok atau Break Even Point (BEP) proyek adalah jumlah unit yang harus dijual atau nilai minimal yang harus diperoleh dari sebuah gagasan bisnis agar dapat mengembalikan semua investasi yang dikeluarkan.Formulasi penentuan titik impas dengan teknik persamaan dapat dilakukan dengan dua cara yakni sebagai berikut:

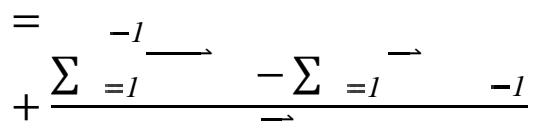

Dimana:

$\mathrm{BEP}=$ Break Even Point $\mathrm{T}_{\mathrm{p}-1}=$ Tahun sebelum terdapat BEP $\mathrm{TC}_{\mathrm{i}}=$ Jumlah total cost yang telah didiskon 
$\mathrm{B}_{\text {icp-1 }}=$ Jumlah benefit yang telah didiskon sebelum BEP

$\mathrm{B}_{\mathrm{p}}=$ Jumlah benefit pada BEP

\section{HASIL DAN PEMBAHASAN \\ Investasi Usaha Agroindustri Tahu Mbak Rubingah}

Biaya investasi yang ada pada usaha Agroindustri Tahu Mbak Rubingah Di Desa Kuantan Sako Kecamatan Logas Tanah Darat Kabupaten Kuantan Singingi dikeluarkan saat usaha di jalankan yaitu usaha agroindustri tahu. Biaya ini merupakan dana dalam pengadaan barang-barang investasi. Adapun investasi usaha berdasarkan jumlah nya pada usaha Agroindustri Tahu Mbak Rubingah Di Desa Kuantan Sako Kecamatan Logas Tanah Darat Kabupaten Kuantan Singingi dapat dilihat pada tabel 2.

Tabel 2. Biaya Investasi Agroindustri Tahu Mbak Rubingah Di Desa Kuantan Sako Kecamatan Logas Tanah Darat Kabupaten Kuantan Singingi

(Sumber : Data Primer Yang Telah Diolah 2019)

\begin{tabular}{llrc}
\hline No & Tahun & Biaya Investasi & $\mathbf{( \% )}$ \\
\hline 0 & 2011 & $27,072,000.00$ & $31.42 \%$ \\
1 & 2012 & $58,800,000.00$ & $68.24 \%$ \\
2 & 2013 & & \\
3 & 2014 & $150,000.00$ & $0.17 \%$ \\
4 & 2015 & & \\
5 & 2016 & & \\
6 & 2017 & $150,000.00$ & $0.17 \%$ \\
7 & 2018 & & \\
\hline \multicolumn{5}{c}{ Total } & $\mathbf{8 6 , 1 7 2 , 0 0 0 . 0 0}$ & $\mathbf{1 0 0 \%}$ \\
\hline
\end{tabular}

Pada tabel 2 dapat diketahui bahwa biaya investasi yang dikeluarkan oleh Agroindustri Tahu Mbak Rubingah dengan total investasi sebesar Rp 86.172.000.00, dimana Agroindustri Tahu Mbak Rubingah terdapat beberapa kali mengeluarkan biaya investasi yaitu pada awal tahun pendirian usaha Agroindustri Tahu Mbak Rubingah sebesar Rp 27.072.000.00 dengan biaya yang dikeluarkan berupa bangunan, alat alat produksi seperti mesin, pencetak tahu, penggaris, pisau, drum, ember, timbangan dan wajan kecil.

Biaya investasi terbesar pada tahun 2012 dengan biaya investasi $\mathrm{Rp}$ 58.800.000.00, biaya yang dikeluarkan berupa renovasi bangunan, penambahan peralatan produksi tahu seperti drum besi, drum plastik, ember, cetakan tahu, dan kain saringan tahu. Besarnya biaya investasi ini dipengaruhi oleh besarnya biaya yang dikeluarkan untuk renovasi bangunan yaitu $\mathrm{Rp}$ 50.000.000.00, hal ini dikarenakan usaha Agroindustri Tahu Mbak Rubingah mulai berkembang.Biaya investasi terkecil dikeluarkan pada tahun 2014 dan tahunn 2017 sebesar Rp 150.000.00, hal ini dikarenakan biaya yang dikeluarkan berupa pembelian drum besi.

\section{Biaya Operasional Agroindustri Tahu Mbak Rubingah}

Menurut Mulyadi (2009), biaya operasional adalah biaya yang terjadi dalam kaitannya dengan operasi yang dilakukan perusahaan dan diukur dalam satuan uang, dimana operasional sering disebut juga operational cost atau biaya usaha.

Biaya operasional biaya yang dikeluarkan oleh usaha Agroindustri Tahu Mbak Rubingah di Desa Kuantan Sako Kecamatan Logas Tanah Darat Kabupeten Kuantan Singingi dapat dilihat pada tabel 3. 
Tabel 3. Biaya Operasional Agroindustri Tahu Mbak Rubingah Di Desa Kuantan Sako Kecamatan Logas Tanah Darat Kabupaten Kuantan Singingi

\begin{tabular}{cllll}
\hline No. Tahun & $\begin{array}{l}\text { Biaya } \\
\text { Operasional }\end{array}$ & $\begin{array}{l}\text { Persentase } \\
(\%)\end{array}$ \\
\hline 0 & 2011 & $141,733,200.00$ & $4.3 \%$ \\
1 & 2012 & $529,276,000.00$ & $16.2 \%$ \\
2 & 2013 & $539,356,000.00$ & $16.5 \%$ \\
3 & 2014 & $544,396,000.00$ & $16.6 \%$ \\
4 & 2015 & $539,356,000.00$ & $16.5 \%$ \\
5 & 2016 & $354,755,920.00$ & $10.8 \%$ \\
6 & 2017 & $354,755,920.00$ & $10.8 \%$ \\
7 & 2018 & $272,199,880.00$ & $8.3 \%$ \\
\hline
\end{tabular}

Total 3,275,828,920.00 100\%

(Sumber: Data Primer yang telah diolah 2019)

Pada tabel 3 dapat dilihat bahwa biaya operasional yang dikeluarkan oleh usaha Agroindustri Tahu Mbak Rubingah dengan rata rata pertahun adalah sebesar $\mathrm{Rp}$ 409.478.615.00 dengan pembagian biaya operasional yang dikeluarkan adalah biaya pembelian bahan baku utama kacang kedelai impor, bahan baku penunjang, bahan bakar, perawatan mesin diesel, pembelian kain saringan dan upah tenaga kerja. Biaya operasional yang dikeluarkan Agroindustri Tahu Mbak Rubingah

Tabel 4. Total Penerimaan Usaha Agroindustri Tahu Mbak Rubingah Di Desa Kuantan Sako Kecamatan Logas Tanah Darat Kabupaten Kuantan Singingi

\begin{tabular}{ccrr}
\hline No & Tahun & Penerimaan & Persentase (\%) \\
\hline 0 & 2011 & $336,000,000.00$ & $5.41 \%$ \\
1 & 2012 & $1,008,000,000.00$ & $16.22 \%$ \\
2 & 2013 & $1,008,000,000.00$ & $16.22 \%$ \\
3 & 2014 & $1,008,000,000.00$ & $16.22 \%$ \\
4 & 2015 & $1,008,000,000.00$ & $16.22 \%$ \\
5 & 2016 & $672,000,000.00$ & $10.81 \%$ \\
6 & 2017 & $672,000,000.00$ & $10.81 \%$ \\
7 & 2018 & $504,000,000.00$ & $8.11 \%$ \\
\hline
\end{tabular}

dengan biaya operasional tertinggi pada tahun 2014 yaitu $\mathrm{Rp}$ 544.396.000.00 dengan biaya terbesar terletak pada pembelian bahan baku utama kedelai impor Rp 398.160.000.00 dan terendah pada perawatan mesin diesel Rp 100.000,00. Sedangkan biaya operasional terendah pada tahun 2011 dikarena perinciaan dana hanya sepuluh bulan terhitung pada awal pendirian investasi tahu Bulan Maret hingga Bulan Desember, biaya yang dikeluarkan sebesar Rp 141.733.200.00 dengan biaya yang terbesar pada pembelian bahan baku kedelai Rp 98.000.000.00, serta biaya terendah pada biaya perawatan mesin diesel sebesar Rp 100.000.00.

\section{Penerimaan Agroindustri Tahu Mbak Rubingah}

Penerimaan adalah jumlah nilai atau hasil penjualan yang diterima dalam menjalankan usaha. Total penerimaan yang diperoleehadalah dari produksi fisik dikalikan dengan harga produksi (Soekartawi: 2006). Adapun total penerimaan yang diterima oleh usaha Agroindustri Tahu Mbak Rubingah berdasarkan jumlah penerimaan pertahun dilihat pada tabel 4 . 


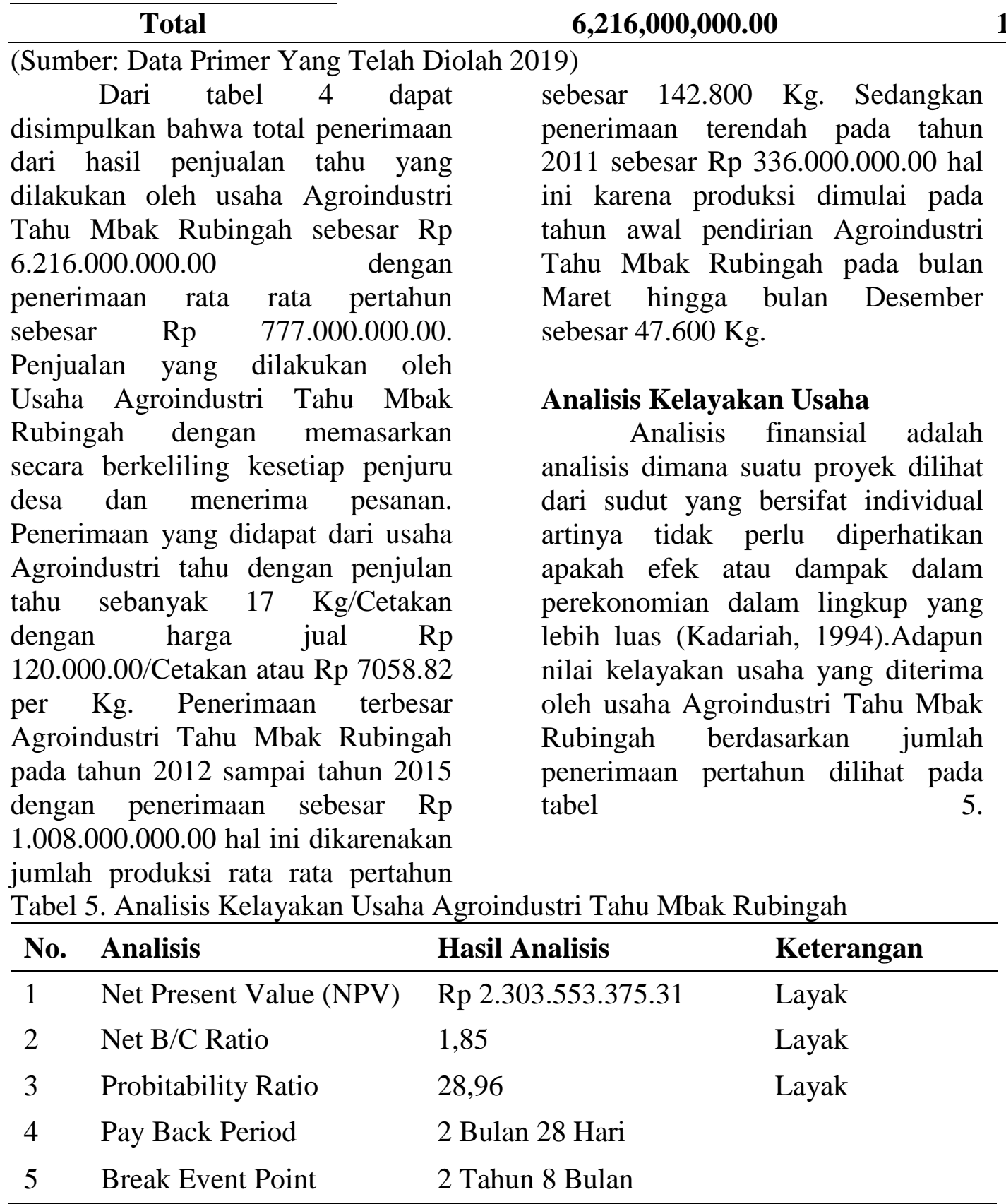

(Sumber: Data Primer Yang Telah Diolah 2019)

\section{Net Present Value (NPV)}

Dari Tabel 5 dapat disimpulkan bahwa Net Present Value (NPV) yang diperoleh oleh usaha Agroindustri Tahu Mbak Rubingah sebesar Rp 2.303.553.375.31 dengan kategori NPV > 0 yang artinya usaha Agroindustri Tahu Mbak Rubingah sangat layak untuk dijalankan. Karena total diskon faktor penerimaan/benefit yang lebih besar yaitu $\mathrm{Rp} 5.027 .589 .278,48$ dari total diskon faktor total biaya/total cost sebesar $\quad \mathrm{Rp} \quad$ 2.724.035.903.18. Dimana kategori kelayak investasi berdasarkan nilai NPV yaitu NPV > 0 , artinya suatu proyek sudah dinyatakan menguntungkan dan layak untuk dijalankan. 


\section{Net Benefit Cost Ratio (Net B/C)}

Net benefit cost Ratioadalah perbandingan antara benefit kotor dengan biaya secara keseluruhan yang telah mengalami compounding. Net Benefit Cost Ratio diperoleh dari perbandingan total present value positif dengan total present value negatif (Ibrahim, 2009).

Nilai Net B/C diperoleh oleh Agroindustri Tahu Mbak Rubingah sebesar $\mathrm{Rp} 1,85$ artinya setiap pengeluaran $\mathrm{Rp} 1$, maka akan menghasilkan pendapatan kotor sebesar $\mathrm{Rp} 1,85$, artinya pengusaha agroindustri tahu masih memperoleh pendapatan bersih sebesar Rp 0,85 dan usaha Agroindustri Tahu Mbak Rubingah berada pada kondisi yang layak untuk dijalankan. Karena total diskon faktor penerimaan/benefit yaitu $\mathrm{Rp}$ 5.027.589.278.48 dibagi total diskon faktor total biaya/total cost sebesar Rp 2.724.035.903.18.

\section{Profitability Ratio (PR)}

Profitability Ratio adalah rasio perbandingan antara selisih benefic dengan biaya operasional dan pemeliharaan dengan jumlah investasi. Profitability Ratio yang diperoleh oleh Agroindustri Tahu Mbak Rubingah sebesar 28,96 maka unit usaha Agroindustri Tahu Mbak Rubingah dinyatakan layak hal ini berdasarkan kriteria $P R>1$ yaitu layak dijalankan.

\section{Pay Back Period (PBP)}

(2012) adalah periode yang diperlukan untuk menutup kembali pengeluaran investasi. Pay Back Period yang diperoleh oleh Agroindustri Tahu Mbak Rubingah selama 2 bulan 28 hari dimana usaha Agroindustri Tahu Mbak Rubingah akan menerima cash in flows atau penerimaan pada bulan ke 2 sehingga usaha Agroindustri Tahu Mbak Rubingah bergerak positif. Karena total diskon faktor biaya investasi yang dikeluarkan Agroindustri Tahu Mbak Rubingah sebesar Rp 82.378.638,23 lebih kecil dari total diskon faktor penerimaan sebesar Rp 336.000.000,00 sehingga pengembalian biaya investasi lebih cepat.

\section{Break Event Point (BEP)}

Menurut Rahardi dan Hartono (2003), Break Even Point (BEP) proyek adalah jumlah unit yang harus dijual atau nilai minimal yang harus diperoleh dari sebuah gagasan bisnis agar dapat mengembalikan semua investasi yang dikeluarkan. Break Event Point yang diperoleh oleh Agroindustri Tahu Mbak Rubingah selama 2 tahun 8 bulan dimana usaha Agroindustri Tahu Mbak Rubingah akan menerima titik balik impas atau tidak dikatakan rugi maupun untung pada tahun ke 2 .

\section{PENUTUP}

\section{Kesimpulan}

Dari hasil penelitian kelayakan usaha Agroindustri Tahu Mbak Rubingah di Desa Kuantan Sako Kecamatan Logas Tanah Darat dapat disimpulkan bahwa :

1. Analisis kelayakan Agroindustri Tahu Mbak Rubingah berdasarkan Net Present Value (NPV) adalah Rp 2.303.553.375.31, nilai Net B/C Ratio sebesar 1,85 dan nilai Profitability Ratio sebesar 28,96 yang bergerak positif.

2. Untuk cas in flow atau Pay Back Period (PBP) Agroindustri Tahu 
Mbak Rubingah pada 2 bulan 28 hari. Sedangkan Break Event Point (BEP) Agroindustri Tahu Mbak Rubingah pada 2 tahun 8 bulan.

\section{Saran}

Berdasarkan hasil penelitian yang telah disimpulkan diatas, maka penulis memberikan saran sebagai berikut :

1. Agroindustri Tahu Mbak Rubingah Di Desa Kuantan Sako layak dijalankan dan dikembangkan. Namun, diharapkan Agroindustri Tahu Mbak Rubingah dapat memenuhi kelayakan usaha sesuia yang ditetapkan pemerintah seperti surat izin usaha, dan lainnya.

2. Limbah hasil pengolahan Agroindustri Tahu Mbak Rubingah hendaknya dapat dimanfaatkan secara maksimal, sehingga memiliki nilai tambah pada usaha Agroindustri Tahu Mbak Rubingah.

3. Hendaknya Pemerintah Kabupaten Kuantan Singingi dapat menstabilkan harga dan kontinuitas bahan baku kedelai sehingga agroindustri tahu dapat berkembang.

\section{DAFTAR PUSTAKA}

Cahyadi,W.2007.Kedelai: Khasiat Dan Teknologi. Jakarta: Bumi Aksara.

Ibrahim.Yacob. 2009. Studi Kelayakan Bisnis. Rineka Cipta, Jakarta.

Kadariah. 1994. Pengantar Evaluasi Proyek. Jakarta.Universitas Indonesia.
Mulyadi.2009.Akuntansi

Biaya.Yogyakarta.STIE YPKPN.

Rahardi,F Dan

Hartono.2003.Agribisinis

Peternakan.Ed

Rev.Jakarta.Swadaya.

Soekartawi.2000.Pengantar Agroindustri.Jakarta.Raja Grafind Persada.

Soekartawi.2006. Agribisnis Teori dan Aplikasi.Jakarta. Rajawali Press.

Wijayanto,Dian.2012.Pengantar Manajemen.Jakarta.Gramed ia Pustaka Utama. 